\title{
Dependence of coastal wetland ecosystem respiration on temperature and tides: a temporal perspective
}

\author{
X. Xie, M.-Q. Zhang, B. Zhao, and H.-Q. Guo \\ Coastal Ecosystems Research Station of the Yangtze River Estuary, Ministry of Education Key Laboratory for Biodiversity \\ Science and Ecological Engineering, Institute of Biodiversity Science, Fudan University, Shanghai 200433, China
}

Correspondence to: H.-Q. Guo (hqguo@fudan.edu.cn)

Received: 27 December 2012 - Published in Biogeosciences Discuss.: 8 March 2013

Revised: 21 August 2013 - Accepted: 16 December 2013 - Published: 3 February 2014

\begin{abstract}
Variations in temperature are widely invoked to explain fluctuations in ecosystem respiration (ER), but hydrological conditions also influence ER. Many researchers have observed that aperiodic variations in hydrological conditions affect ER and the associated temperature sensitivity. However, little is known about how periodic hydrological dynamics affect ER and its relationship with temperature on different timescales. In the present study, data from two coastal wetland sites were used to compare the variations in thermal and tidal influences on ER at three timescales (monthly, seasonal, and semiannual), and we found that (1) the influences of tides and temperature on ER varied with time. Especially in summer, the ER exhibited periodic dynamics regulated by tides; (2) in the temporal domain, temperature was dominant at the semiannual and seasonal scales, while the tidal effect was dominant at the monthly scale. In the spatial domain, the relative importance of temperature was greater at higher elevation sites, while tides exerted more influence at lower elevation sites; (3) the monthly model with tidal effect performed best, while regression models at semiannual and seasonal scales generated systematic errors in ER. These results demonstrate that, for coastal wetlands, the application of parameters from regression models based on long-term (seasonal or semiannual) data should be avoided in gap filling, and the effects of tides and elevation should be considered in estimating the carbon budget.
\end{abstract}

\section{Introduction}

Temperature and the hydrological conditions are considered the two most important regulating factors of ecosystem respiration (ER) (Bubier et al., 2003; Griffis et al., 2004). Whereas temperature is often regarded as the dominant factor, especially for areas with sufficient water, the hydrological conditions are often regarded as the secondary factor that moderates ER through the relationship between temperature and respiration. Most of the variations in respiration on the annual or seasonal scale can be described by the exponential function with an independent variable (i.e., temperature) and a constant temperature sensitivity (i.e., $Q_{10}$ ) (Lafleur et al., 2005; Tang et al., 2008). However, a fixed $Q_{10}$ may ignore the influence of the hydrological conditions at the monthly or weekly timescale (Janssens and Pilegaard, 2003; Reichstein et al., 2005; Fierer et al., 2006). The hydrological conditions tend to become the limiting factor of respiration in summer, as the temperature is high and relatively constant, but in winter the low temperature becomes the limiting factor (Flanagan and Johnson, 2005; DeForest et al., 2006). Thus, a fixed $Q_{10}$ could be inappropriate because the main driving mechanism of ER may alternate.

There is much evidence that ER is affected by hydrological conditions. In most ecosystems, soil moisture and ER are positively correlated (Xu and Qi, 2001; Qi et al., 2002; Reichstein et al., 2002; Flanagan and Johnson, 2005; Maseyk et al., 2008), as increasing soil moisture relieves water depression. Even so, DeForest et al. (2006) reported a negative correlation between soil moisture and $Q_{10}$ for an oakdominated forest, where the respiration level and $Q_{10}$ in the growing season were lower in wetter years. A rising water 

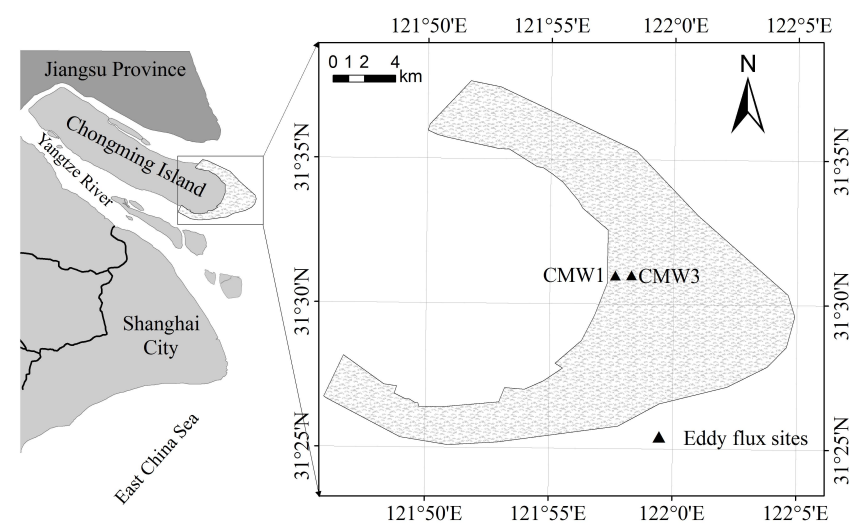

Fig. 1. Location of research sites.

level commonly has a negative effect on respiration in a wetland (DeBusk and Reddy, 2003; Hirota et al., 2007; Juszczak et al., 2013), as this reduces the available soil oxygen concentration. In some cases, the oxygen concentration is even near zero in the near-surface layer (Lafleur et al., 2005). Therefore, drought in a wetland tends to increase the respiration level and the $Q_{10}$ magnitude (Savage and Davidson, 2001; Bubier et al., 2003; Phillips et al., 2010).

Most of the previous research has focused on the seasonal variation in hydrological conditions and the influences on the ecosystem respiration. It is difficult to estimate the relative importance of temperature and hydrological conditions in those ecosystems, as the hydrological conditions have seasonal dynamics similar to that of temperature (Davidson et al., 2006). Apparently, this co-variation leads to inaccurate estimates of $Q_{10}$ (Reichstein et al., 2005). Compared to other wetland ecosystems, the coastal wetland is affected by a special periodic hydrological condition (i.e., the tide). Guo et al. (2009) found that the tidal activities had a significant effect on the $\mathrm{CO}_{2}$ flux of a coastal wetland ecosystem at 15-day period. As tides do not co-vary with temperature, it would be convenient to separate the influences of tides and temperature.

In the present study, we used continuous flux data to investigate the relative influences of temperature and tides on ER at three timescales. We attempted to determine (1) whether the ER exhibits periodic variation corresponding to the tidal cycle, (2) how and why the relative importance of temperature and tides change with time on different timescales, and (3) which timescale is the best choice for coastal wetland ER estimation.

\section{Materials and methods}

\subsection{Study area}

Our study area is located in the eastern part of Chongming Island (Fig. 1). The area has a subtropical monsoon climate, and the annual precipitation was $800-900 \mathrm{~mm}$ from 2005 to 2007. The mean temperature and mean relative humidity over those $3 \mathrm{yr}$ were $16.5^{\circ} \mathrm{C}$ and $77.7 \%$. The suitable temperature range and the ample rainfall create a long growing season from March to November. The dominant plant species are Phragmites australis, Scirpus mariqueter, and Spartina alterniflora. Spring begins in early April and ends in mid-June. Autumn begins in late September and ends in late November.

The tides have a mixed semidiurnal pattern, which means that there are two high tides and two low tides each day with different heights, and there are spring tides and neap tides with roughly 15 -day period. There are three observation sites in the study area, but only two (denoted CMW1 and CMW3) were chosen for analysis, since CMW1 $\left(31^{\circ} 31.0^{\prime} \mathrm{N}\right.$, $\left.121^{\circ} 57.6^{\prime} \mathrm{E}\right)$ and CMW3 $\left(31^{\circ} 31.0^{\prime} \mathrm{N}, 121^{\circ} 58.3^{\prime} \mathrm{E}\right)$ are located along the elevation gradient (Fig. 1). Both sites experience inundation by seawater at spring tide.

Each site was equipped with the same instruments. $\mathrm{CO}_{2}$ flux was measured at $5 \mathrm{~m}$ above ground level by the eddy covariance method. A three-axis sonic anemometer (CSAT3, Campbell Scientific, USA) measured high-frequency $(10 \mathrm{~Hz})$ wind velocity and sonic temperature, while an open-path infrared gas analyzer ( $\mathrm{Li}-7500, \mathrm{Li}-\mathrm{COR}, \mathrm{USA})$ measured $\mathrm{CO}_{2}$ and $\mathrm{H}_{2} \mathrm{O}$ densities at the same frequency. The air temperature probes were mounted at 1.6, 2.7, and $4.8 \mathrm{~m}$ above ground level. A water content reflectometer (CS616, Campbell Scientific, USA) was installed to observe the volume water content (VWC) of soil $5 \mathrm{~cm}$ deep.

\subsection{Handling of ecosystem respiration (ER) data}

$\mathrm{CO}_{2}$ fluxes were computed from 30 min covariance of wind velocity and $\mathrm{CO}_{2}$ density. We discarded the $30 \mathrm{~min}$ data that were measured during rain. The actual flux data without any gap filling were used to avoid any potential bias introduced by a gap-filling algorithm.

Nighttime flux data were taken as equivalent to ER. To obtain continuous nighttime data rather than break these into two parts, we set the beginning of a day at noon. For example, day of year (DOY) 1 begins on 1 January 12:00 LT and ends on 2 January 12:00 LT. Solar elevation angles were used to separate the daytime and nighttime. We consider nighttime to have solar elevation angles less than $-6^{\circ}$. The solar elevation angles are computed from the longitude and latitude of each site.

Averages of daily nighttime flux data and corresponding standard error were calculated. Because of quality control, rejection rates varied greatly from day to day. For reliable averages, each day must have at least five valid values and the standard error must not exceed 1.25 times the average. 


\subsection{Quantification of tidal effect}

As there was a lack of field records of tidal elevation, tide tables from the nearest tidal station (at Hengsha) were used. The tidal elevations were integrated into diel values by extracting the maximum value for each night. In a 15-day tidal cycle, the day with the maximum tidal elevation was marked as 0 , and the other days were marked from -7 to 7 according to the distance from the nearest spring tide. For example, -1 means 1 day before the spring tide and 1 means 1 day after the spring tide. To quantify the tidal effect, we devised an index $J_{\mathrm{TEI}}$ that represents the ratio of the actual ER to the highest potential ER without a tidal effect. This index is calculated as follows:

$J_{\mathrm{TEI}}=\mathrm{TEI} \cdot(1-s)+s$,

where TEI is the normalized variation of ER in tidal cycles and $s$ is a tidal effect parameter. The normalized value TEI ranges from 0 to 1 . The fitted parameter $s$ equals the ratio of the lowest ER to the highest ER in a tidal cycle and thus actually describes the magnitude of the tidal influence within a period. A smaller value of $s$ corresponds to a greater tidal influence.

\subsection{ANOVA and error assessment}

A modified exponential function was used in our study, and we supposed that the tide is a downward regulator of ER in coastal wetland. The variable $J_{\text {TEI }}$ was used as a multiplier for the exponential function. Air temperature $\left(T_{\mathrm{a}}\right)$ was chosen as the argument, as this is more easily sensed than soil temperature and explains more variances of ER (Reichstein et al., 2005). Hence, the ecosystem respiration was expressed as

$\mathrm{ER}=J_{\mathrm{TEI}} R_{0} e^{k \cdot T_{\mathrm{a}}} \varepsilon$,

where $R_{0}$ and $k$ are fitted parameters and $\varepsilon$ is the error caused by other environmental factors. The temperature sensitivity $Q_{10}$ was calculated from $k$ as

$Q_{10}=e^{10 k}$.

The following logarithmic form of Eq. (2) was used in the analysis of variance (ANOVA):

$\ln (\mathrm{ER})=\ln \left(R_{0}\right)+k \cdot T_{\mathrm{a}}+\ln \left(J_{\mathrm{TEI}}\right)+\ln (\varepsilon)$.

Considering that the semidiurnal tide has a 15-day period and there is the possibility of failure caused by insufficient data, we selected three window lengths of 1,3 , and 6 months to represent monthly, seasonal, and semiannual timescales. Each month was separated on the basis of the lunar calendar and contained either 29 or 30 days.

To prevent overfitting of the model, the results with residual degrees of freedom fewer than three were removed. The ratio $C_{\text {Factor }}$ (or $R^{2}$ ) between the sum of squares of a factor $\left(\mathrm{SS}_{\mathrm{Factor}}\right)$ and the total sum of squares $\left(\mathrm{SS}_{\mathrm{Total}}\right)$ was used to measure the relative importance of that factor as follows:

$$
\begin{array}{r}
C_{T_{\mathrm{a}}}=\mathrm{SS}_{\mathrm{T}_{\mathrm{a}}} / \mathrm{SS}_{\text {Total }}, \\
C_{\text {Tide }}=\mathrm{SS}_{\mathrm{J}_{\mathrm{TEI}}} / \mathrm{SS}_{\mathrm{Total}} .
\end{array}
$$

Hence, $C_{T_{\mathrm{a}}}$ and $C_{\text {Tide }}$ equal the proportions of total variation in ER that can be explained by temperature and tides, respectively.

\section{Results}

\subsection{Variation of ER and environmental factors}

The respiration level at CMW1 was slightly higher than that at CMW3. The ER exhibited similar significant seasonal changes at the two sites from 2005 to 2007 . The low values in winter were slightly above zero. The peak value reached $12.0 \mu \mathrm{mol} \mathrm{m}^{-2} \mathrm{~s}^{-1}$ at CMW1 and $10.1 \mu \mathrm{mol} \mathrm{m}^{-2} \mathrm{~s}^{-1}$ at CMW3. The air temperature measurements from the two sites were almost same, with both exhibiting strong seasonal dynamics. There is obviously a correlation between ER and air temperature on the annual scale for each site. Because of the high moisture content of the soil, the VWC at each site was near 1 in winter and early spring but ranged from 0.6 to 0.7 in mid-summer, so the seasonal dynamics of the VWC was similar to that of the air temperature.

A periodicity in the dynamics of the ER was observed during spring-neap tidal cycles in early summer (DOY 200 230). The air temperature during this period was relatively stable, varying from 26.5 to $27.5^{\circ} \mathrm{C}$. There was an obvious hysteresis between the ER variations and the tidal elevation. The ER reached its maximum 3 days after the neap tide at CMW3 (average $8.59 \mu \mathrm{mol} \mathrm{m}^{-2} \mathrm{~s}^{-1}$ ) and 4 days after the neap tide at CMW1 (average $9.65 \mu \mathrm{mol} \mathrm{m}^{-2} \mathrm{~s}^{-1}$ ). The ER reached its minimum 1 day after spring tide at both sites, with averages of $3.86 \mu \mathrm{mol} \mathrm{m}^{-2} \mathrm{~s}^{-1}$ at CMW1 and $2.75 \mu \mathrm{mol} \mathrm{m}^{-2} \mathrm{~s}^{-1}$ at CMW3 (Fig. 2).

\subsection{Relative importance of temperature and tides on three timescales}

Air temperature $\left(T_{\mathrm{a}}\right)$ can explain from 0 to $93.1 \%$ of the variations in the observed $\mathrm{ER}$, and the relative importance of tides ranged from 0 to $78.8 \%$. The relative importance of $T_{\mathrm{a}}$ and tides are highly variable with time, especially on the monthly scale. Temperature was the dominant factor from late winter to early spring (February to May) and in autumn (September to November), while the tide was the dominant factor in summer (June, July, and August) (Fig. 3). As the timescale was made larger, the relative importance of each factor became constant. At the semiannual scale, temperature explained over half of the variations (51.9-93.1\%) in the observed ER at each site, while tides explained only $0.3-1.1 \%$ (Fig. 3). 


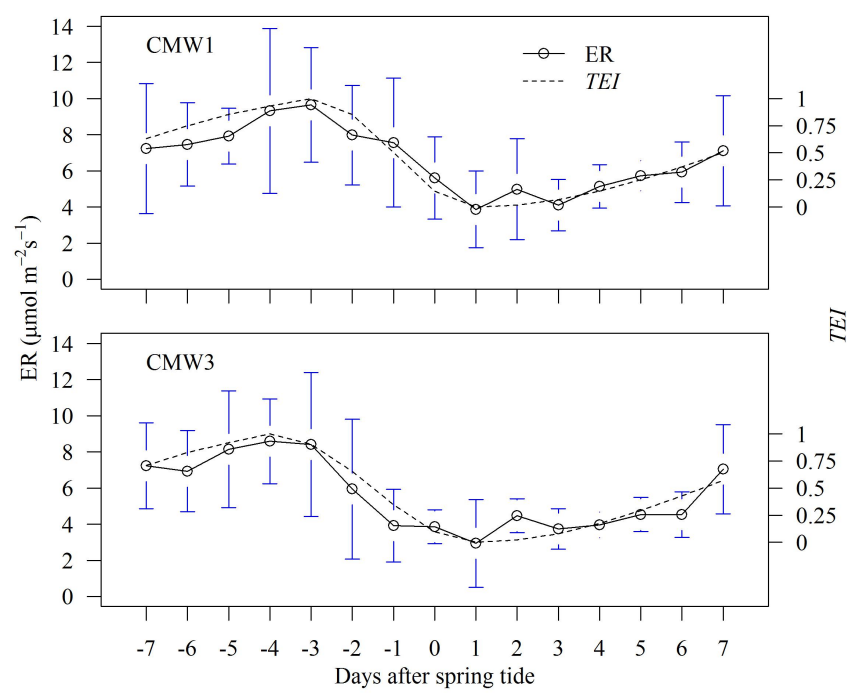

Fig. 2. Variation of ER (ecosystem respiration) during spring-neap tidal cycles in summer. Solid line represents ER, and dashed line represents normalized fit of TEI (tidal effect index). Top plot is for CMW1, and bottom plot is for CMW3.

The mean relative importance of $T_{\mathrm{a}}$ was much higher on the semiannual scale than on the seasonal scale or the monthly scale. That is, the semiannual $\mathrm{C}_{T_{\mathrm{a}}}$ was $85.3 \%$ for CMW1 versus $78.9 \%$ for CMW3, the seasonal $\mathrm{C}_{T_{\mathrm{a}}}$ was $64.9 \%$ for CMW1 versus $44.0 \%$ for CMW3, and the monthly $C_{T_{\mathrm{a}}}$ was $51.2 \%$ for CMW1 versus $37.1 \%$ for CMW3. $T_{\mathrm{a}}$ had a much greater influence at the semiannual scale than at the monthly scale, while the tide had an opposite alternation. The mean relative importance of tides was slightly greater for CMW3 than for CMW1 (Fig. 3). That is, the monthly $C_{\text {Tide }}$ was $11.2 \%$ for CMW3 versus $11.0 \%$ for CMW1, the seasonal $C_{\text {Tide }}$ was $7.5 \%$ for CMW3 versus $5.8 \%$ for CMW1, and the semiannual $C_{\text {Tide }}$ was $5.1 \%$ for CMW3 versus $1.8 \%$ for CMW1.

\subsection{Factors that affect the relative importance}

The relative importance of air temperature $\left(C_{T_{\mathrm{a}}}\right)$ is determined by the magnitude of temperature sensitivity $\left(Q_{10}\right)$ as well as the variance of air temperature. When the variance of $T_{\mathrm{a}}$ was greater than 10 , the value of $C_{T_{\mathrm{a}}}$ tended to exceed 0.5. The magnitude of $Q_{10}$ also had an influence on $C_{T_{\mathrm{a}}}$. For a given variance of $T_{\mathrm{a}}$, a higher $Q_{10}$ corresponded to a higher relative importance of $T_{\mathrm{a}}$ (Fig. 4). As the vertical dashed lines in Fig. 4 show, the variance of $T_{\mathrm{a}}$ had a significant positive correlation with timescale. This explains why temperature had a greater influence at the semiannual scale than at the monthly scale.

Note that when the temperature variance is low (usually less than 5), the $Q_{10}$ value may be unreliable. For example, the $Q_{10}$ value of the blue dot marked with an arrow is 66.7, which is an unreasonably high value. However, if we incor-

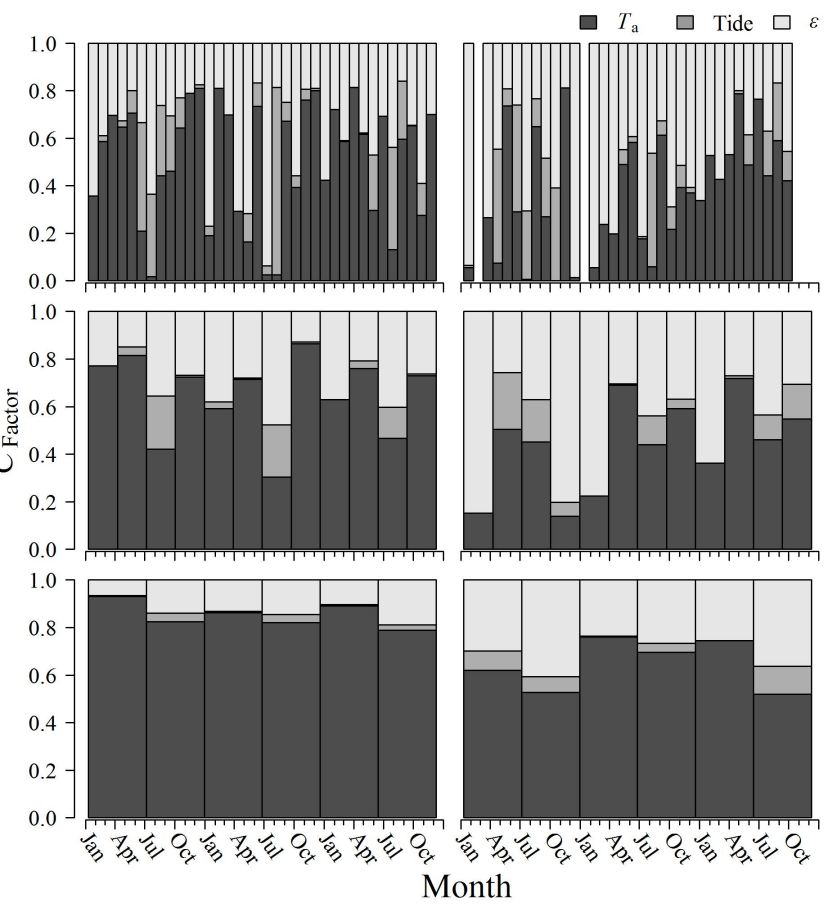

Fig. 3. Variation of $C_{\text {Factor }}$ (relative importance of environmental factor) on monthly (top), seasonal (middle), and semiannual (bottom) scales. Left side is for CMW1, and right side is for CMW3. Each bin is defined by the lunar calendar, but ticks on the horizontal axes reflect the Gregorian calendar.

porate the monthly average temperature $\left(17.4^{\circ} \mathrm{C}\right)$ and the corresponding $R_{0}\left(4.88 \times 10^{-3} \mu \mathrm{mol} \mathrm{m}{ }^{-2} \mathrm{~s}^{-1}\right)$ into Eq. (1) and set $s$ to 1 (meaning no tidal effect), then a reasonable ER $\left(7.28 \mu \mathrm{mol} \mathrm{m}^{-2} \mathrm{~s}^{-1}\right)$ is produced. Apparently, the error was caused by the weak correlation between temperature and ER rather than by inferior observations.

By definition, the magnitude of $s$ reflects the influence of tides. Even so, the same value of $s$ corresponded to a much smaller $C_{\text {Tide }}$ at the semiannual scale than at the monthly scale (Fig. 5), which implies that the tidal effect may be underestimated by a long-term model.

\subsection{Assessment of regression}

The median distribution (systematic error) is $[-0.34,0.44]$ for the semiannual model, $[-0.17,0.26]$ for the seasonal model (not shown), $[-0.069,0.11]$ for the monthly model with a tidal effect, and $[-0.071,0.14]$ for the monthly model without a tidal effect. Note that $\alpha$ is 0.05 for all intervals. The distribution of whisker lengths (uncertainty) is [0.36, 2.02] for the semiannual model, $[0.38,1.52]$ for the monthly model with a tidal effect, and $[0.50,1.77]$ for the monthly model without a tidal effect.

The relative errors of the semiannual and seasonal models were higher than those of the monthly models. The median relative error of each month was not always close to zero 


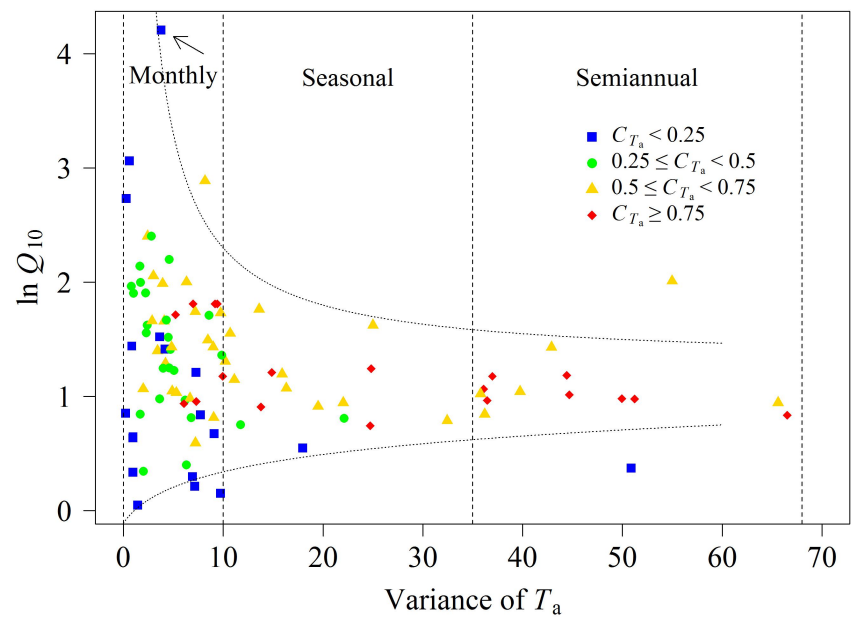

Fig. 4. Vertical dashed lines show the typical ranges of variance of $T_{\text {a }}$ (air temperature) on three temporal scales. Dotted curves show the boundaries of $Q_{10}$ distribution. Different colors represent different levels of $\mathrm{C}_{T_{\mathrm{a}}}$ (relative importance of air temperature).

in the semiannual and seasonal models, which indicated that the respiration level was underestimated in spring and overestimated in winter (the seasonal model is not shown). The monthly models had much smaller systematic errors (medians close to zero) and much smaller uncertainties (shorter whiskers) than the semiannual and seasonal models (Fig. 6).

The semiannual and seasonal models had similar absolute errors of $0.0554 \pm 1.97 \mu \mathrm{mol} \mathrm{m}^{-2} \mathrm{~s}^{-1}$ and $0.0562 \pm 1.91 \mu \mathrm{mol} \mathrm{m}^{-2} \mathrm{~s}^{-1}$, respectively. The absolute error of the monthly model without a tidal effect was $0.0326 \pm 2.10 \mu \mathrm{mol} \mathrm{m}^{-2} \mathrm{~s}^{-1}$, and the uncertainty was still large even though the median (systematic error) was much smaller. Including the tidal effect in the monthly model greatly improved the performance, which reduced the absolute error to $0.0273 \pm 1.52 \mu \mathrm{mol} \mathrm{m}^{-2} \mathrm{~s}^{-1}$, and reduced the uncertainty by $20 \%$, mainly in summer (Fig. 6). The Akaike information criterion (AIC) of the monthly model was significantly smaller $(p<0.05)$ with the tidal effect than without.

\section{Discussion}

\subsection{Variation in relative importance of tide}

The wetland environment has to meet some requirements for the hydrological conditions to exert an influence on ER: (1) the ecosystem must suffer from low water content or be restrained by high water content (Reichstein et al., 2003); and (2) the hydrological conditions must have enough variation. Most wetlands conform to the first requirement, but some do not conform to the second. Lafleur et al. (2005) reported that the ER of a bog was not determined by water table depth (WTD) and explained that a small change in WTD would not

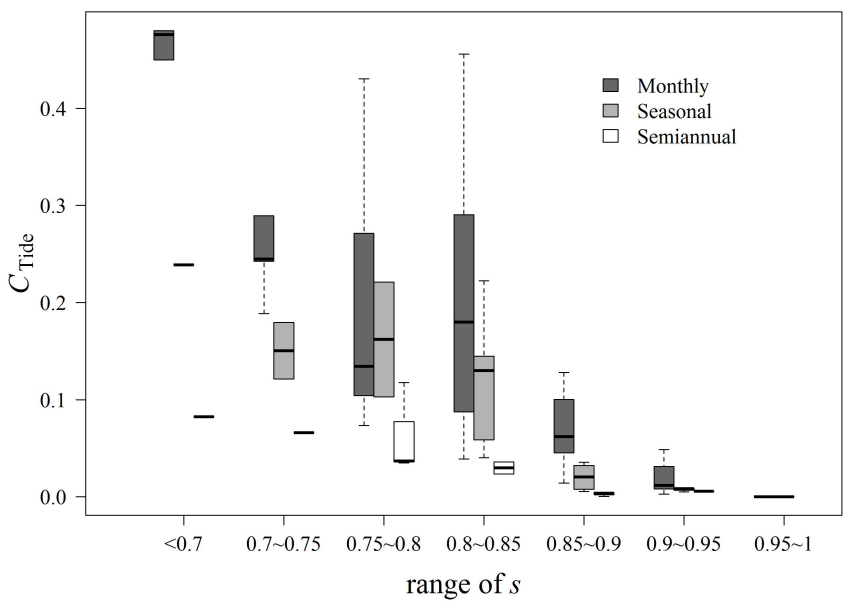

Fig. 5. Relationships between $C_{\text {Tide }}$ and $s$ on different temporal scales. Monthly scale has much higher $C_{\text {Tide }}$ (relative importance of tides) than semiannual scale, while $s$ (tidal effect parameter) is less than 0.9 .

produce enough influence on the surface layer of soil where most of the $\mathrm{CO}_{2}$ was produced and released. The tidal activity satisfies both requirements. The intrusion of seawater in the spring tide period covers the soil surface, which impedes the production and release of $\mathrm{CO}_{2}$, and the low water level in the neap tide period creates a relative dry environment, which increases the respiration rate (Hirota et al., 2007). Compared to the seasonal change of hydrological conditions and the associated ER in other ecosystems (Bubier et al., 2003; DeForest et al., 2006), the tidal activity in coastal wetlands results in tremendous periodic variation of ER in a 15-day cycle (Guo et al., 2009).

The different conditions of winter and summer caused a seasonal shift in tidal influence. In winter, the low temperature, short duration of sunlight, and death of plants all weakened the evapotranspiration and thus maintained the soil water content at saturation. This resulted in a wet environment that the hydrological conditions were unable to provide enough variation (Lafleur et al., 2005). In summer, the temperature was high and stable, so the VWC was significantly lower than in the winter, when the tidal water can easily change the water content of the surface soil layer. The relative importance of tides is slightly higher at the lower elevation site, and therefore the tidal influence on coastal wetlands has not only a temporal variation but also a spatial variation (Hirota et al., 2007). It would be necessary to consider elevation while estimating the regional respiration of a coastal wetland.

\subsection{Regression at three timescales}

Recently, whether short-term $Q_{10}$ would provide more precise results has become controversial. DeForest et al. (2006) showed with an annual model that the passive response of 

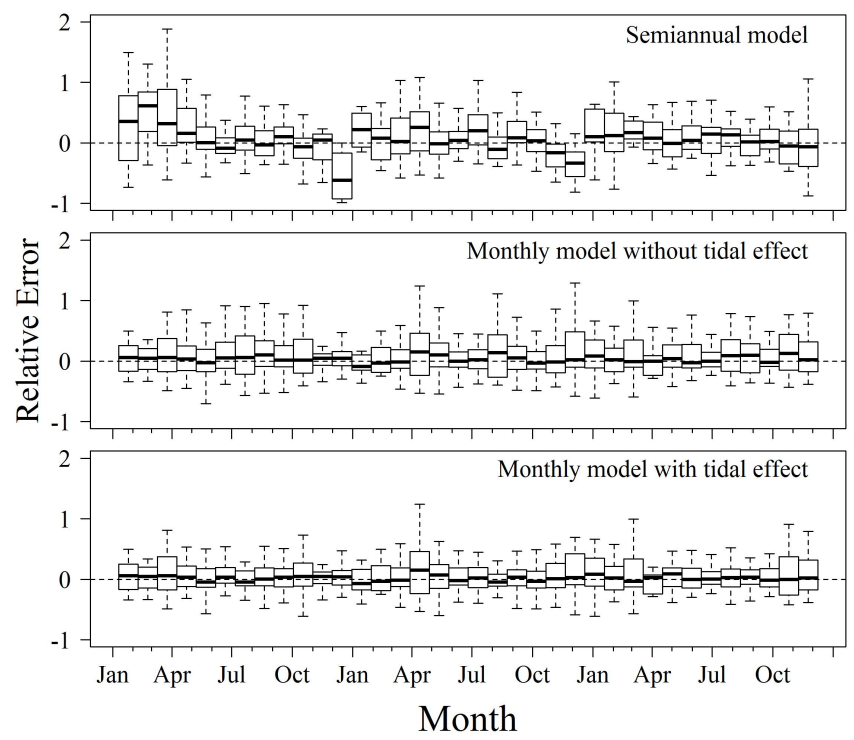

Fig. 6. Relative errors of monthly model (with and without tidal effect) and semiannual model. Compared to the semiannual model (top), the monthly models (bottom and middle) have smaller relative error, and the median of each bin is close to zero. The semiannual model overestimates the respiration in spring and underestimates that in winter. Including the tidal effect in the monthly model helps to reduce the error for summer (bottom vs. middle).

summer ER to temperature in a forest ecosystem resulted in underestimated summer respiration and overestimated winter respiration. In our study, the semiannual and seasonal models also produced large systematic errors: underestimation of winter respiration and overestimation of spring respiration as the drier summer environment stimulated the ER. Reichstein et al. (2005) compared the temperature sensitivities derived from long-term (annual) data and short-term (mainly 7- and 15-day) data and concluded that short-term $Q_{10}$ reduced the so-called confounding effect of the other factors. Our results confirm that confounding is reduced by a short-term model, as the monthly models had smaller systematic errors than the semiannual and seasonal models. In contrast, Janssens and Pilegaard (2003) believed that short-term $Q_{10}$ derived from 4- to 7-day data was confounded by other factors. As a result of the alternation of the driving mechanism in summer, incorporating the tidal effect into the monthly model reduced the systematic errors and eliminated $20 \%$ of the uncertainties. Clearly, there are two kinds of so-called confounding effects. The monthly model helps to reduce the long-term confounding effects that are caused by passive and active responses to temperature on the seasonal scale, whereas incorporating the tidal effect helps to reduce the short-term confounding effect that is caused by the alternation of the ER driving mechanism.

Our results show that temperature has a much greater relative importance in the semiannual model than in the monthly model, but $Q_{10}$ derived from the semiannual model was still considered inappropriate. Yuste et al. (2004) explained that a long-term $Q_{10}$ is not only a temperature sensitivity parameter but also a coefficient that includes information on other factors that co-vary with temperature on the semiannual scale. In our study, air temperature had seasonal dynamics similar to that of other factors such as VWC and the phenology of vegetation. Thus, $Q_{10}$ derived from the semiannual or seasonal model also included information on seasonal changes in VWC and vegetation. Reichstein et al. (2005) and Janssens and Pilegaard (2003) both included a test of temperature range to ensure the reliability of $Q_{10}$. Similarly, the larger variance of temperature in the monthly model tends to result in more reliable $Q_{10}$ values and greater temperature sensitivity.

\section{Conclusions}

Data from two coastal wetland sites were used to explore how periodic hydrological dynamics modifies the relationships between ER and temperature on different timescales. The relative importance of temperature and tides varied with time. With a periodic tidal activity, the ER of a coastal wetland exhibited an obvious periodic fluctuation only in summer, when the temperature variance became smaller and tidal activity replaced temperature as the main driving factor. However, this alternation was found only at the monthly scale. The influence of tides is greater at the site with relatively low elevation, while the influence of temperature is greater at the site with relatively high elevation.

With the alternation of the main driving mechanism, the $Q_{10}$ values derived from the semiannual and seasonal models were not appropriate for a coastal wetland, even though the associated $R^{2}$ may be high. Compared to the semiannual and seasonal models, the monthly models reduce the long-term confounding effects and thus reduce the systematic error. Incorporating the tidal effect into the monthly model helps to reduce the short-term confounding effect, which minimizes the uncertainty and systematic errors.

Acknowledgements. This research was financially supported by the National Basic Research Program of China (no. 2013CB430404), the Natural Science Foundation of China (no. 31170450, 31100409), and Shanghai Science and Technology Innovation Action Plan (no. 13JC1400400, 13231203503). Thanks to D. Wang, H.-B. Wang, H. Li, R. Zhang and X.-H. Zhang for provided helpful criticism to manuscript.

Edited by: R. Conant 


\section{References}

Bubier, J., Crill, P., Mosedale, A., Frolking, S., and Linder, E.: Peatland responses to varying interannual moisture conditions as measured by automatic $\mathrm{CO}_{2}$ chambers, Global Biogeochem. Cy., 17, 1066, doi:10.1029/2002GB001946, 2003.

Davidson, E. A., Janssens, I. A., and Luo, Y.: On the variability of respiration in terrestrial ecosystems: moving beyond $Q_{10}$, Global Change Biol., 12, 154-164, 2006.

DeBusk, W. F. and Reddy, K. R.: Nutrient and hydrology effects on soil respiration in a northern everglades marsh, J. Environ. Qual., 32, 702-710, 2003.

DeForest, J. L., Noormets, A., McNulty, S. G., Sun, G., Tenney, G., and Chen, J. Q.: Phenophases alter the soil respirationtemperature relationship in an oak-dominated forest, Int. J. Biometeorol., 51, 135-144, 2006.

Fierer, N., Colman, B. P., Schimel, J. P., and Jackson, R. B.: Predicting the temperature dependence of microbial respiration in soil: a continental-scale analysis, Global Biogeochem. Cy., 20, GB3026, doi:10.1029/2005GB002644, 2006.

Flanagan, L. B. and Johnson, B. G.: Interacting effects of temperature, soil moisture and plant biomass production on ecosystem respiration in a northern temperate grassland, Agr. Forest Meteorol., 130, 237-253, 2005.

Griffis, T. J., Black, T. A., Gaumont-Guay, D., Drewitt, G. B., Nesic, Z., Barr, A. G., Morgenstern, K., and Kljun, N.: Seasonal variation and partitioning of ecosystem respiration in a southern boreal aspen forest, Agr. Forest Meteorol., 125, 207-223, 2004.

Guo, H. Q., Noormets, A., Zhao, B., Chen, J. Q., Sun, G., Gu, Y. J., Li, B., and Chen, J. K.: Tidal effects on net ecosystem exchange of carbon in an estuarine wetland, Agr. Forest Meteorol., 149, 1820-1828, , 2009.

Hirota, M., Senga, Y., Seike, Y., Nohara, S., and Kunii, H.: Fluxes of carbon dioxide, methane and nitrous oxide in two contrastive fringing zones of coastal lagoon, Lake Nakaumi, Japan, Chemosphere, 68, 597-603, 2007.

Janssens, I. A. and Pilegaard, K.: Large seasonal changes in $Q_{10}$ of soil respiration in a beech forest, Global Change Biol., 9, 911918, 2003.

Juszczak, R., Humphreys, E., Acosta, M., Michalak-Galczewska, M., Kayzer, D., and Olejnik, J.: Ecosystem respiration in a heterogeneous temperate peatland and its sensitivity to peat temperature and water table depth, Plant Soil, 366, 505-520, 2013.

Lafleur, P. M., Moore, T. R., Roulet, N. T., and Frolking, S.: Ecosystem respiration in a cool temperate bog depends on peat temperature but not water table, Ecosystems, 8, 619-629, 2005.

Maseyk, K., Grunzweig, J. M., Rotenberg, E., and Yakir, D.: Respiration acclimation contributes to high carbon-use efficiency in a seasonally dry pine forest, Global Change Biol., 14, 1553-1567, 2008.
Phillips, S. C., Varner, R. K., Frolking, S., Munger, J. W., Bubier, J. L., Wofsy, S. C., and Crill, P. M.: Interannual, seasonal, and diel variation in soil respiration relative to ecosystem respiration at a wetland to upland slope at Harvard Forest, J. Geophys. Res.Biogeo., 115, G02019, 2010.

Qi, Y., Xu, M., and Wu, J. G.: Temperature sensitivity of soil respiration and its effects on ecosystem carbon budget: nonlinearity begets surprises, Ecol. Model., 153, 131-142, 2002.

Reichstein, M., Tenhunen, J. D., Roupsard, O., Ourcival, J. M., Rambal, S., Dore, S., and Valentini, R.: Ecosystem respiration in two mediterranean evergreen Holm Oak forests: drought effects and decomposition dynamics, Funct. Ecol., 16, 27-39, 2002.

Reichstein, M., Rey, A., Freibauer, A., Tenhunen, J., Valentini, R., Banza, J., Casals, P., Cheng, Y. F., Grunzweig, J. M., Irvine, J., Joffre, R., Law, B. E., Loustau, D., Miglietta, F., Oechel, W., Ourcival, J. M., Pereira, J. S., Peressotti, A., Ponti, F., Qi, Y., Rambal, S., Rayment, M., Romanya, J., Rossi, F., Tedeschi, V., Tirone, G., $\mathrm{Xu}, \mathrm{M}$., and Yakir, D.: Modeling temporal and large-scale spatial variability of soil respiration from soil water availability, temperature and vegetation productivity indices, Global Biogeochem. Cy., 17, 1104, doi:10.1029/2003GB002035, 2003.

Reichstein, M., Falge, E., Baldocchi, D., Papale, D., Aubinet, M., Berbigier, P., Bernhofer, C., Buchmann, N., Gilmanov, T., Granier, A., Grunwald, T., Havrankova, K., Ilvesniemi, H., Janous, D., Knohl, A., Laurila, T., Lohila, A., Loustau, D., Matteucci, G., Meyers, T., Miglietta, F., Ourcival, J. M., Pumpanen, J., Rambal, S., Rotenberg, E., Sanz, M., Tenhunen, J., Seufert, G., Vaccari, F., Vesala, T., Yakir, D., and Valentini, R.: On the separation of net ecosystem exchange into assimilation and ecosystem respiration: review and improved algorithm, Global Change Biol., 11, 1424-1439, 2005.

Savage, K. E. and Davidson, E. A.: Interannual variation of soil respiration in two New England forests, Global Biogeochem. Cy., 15, 337-350, 2001.

Tang, J. W., Bolstad, P. V., 5 Desai, A. R., Martin, J. G., Cook, B. D., Davis, K. J., and Carey, E. V.: Ecosystem respiration and its components in an old-growth forest in the Great Lakes region of the United States, Agr. Forest Meteorol., 148, 171-185, 2008.

$\mathrm{Xu}, \mathrm{M}$. and Qi, Y.: Spatial and seasonal variations of $Q_{10}$ determined by soil respiration measurements at a Sierra Nevadan forest, Global Biogeochem. Cy., 15, 687-696, 2001.

Yuste, J. C., Janssens, I. A., Carrara, A., and Ceulemans, R.: Annual $Q_{10}$ of soil respiration reflects plant phenological patterns as well as temperature sensitivity, Global Change Biol., 10, 161169, 2004. 